\title{
Operationalizing inclusive innovation: lessons from innovation platforms in livestock value chains in India and Mozambique
}

Kees Swaans, Birgit Boogaard, Ramkumar Bendapudi, Hailemichael Taye, Saskia Hendrickx \& Laurens Klerkx

To cite this article: Kees Swaans, Birgit Boogaard, Ramkumar Bendapudi, Hailemichael Taye, Saskia Hendrickx \& Laurens Klerkx (2014) Operationalizing inclusive innovation: lessons from innovation platforms in livestock value chains in India and Mozambique, Innovation and Development, 4:2, 239-257, DOI: 10.1080/2157930X.2014.925246

To link to this article: http://dx.doi.org/10.1080/2157930X.2014.925246 \section{(c) 2014 The Author(s). Published by Taylor \&
Francis.}

Submit your article to this journal $\pi$

View related articles \ulcorner
曲 Published online: 27 Jun 2014.

III Article views: 1444

View Crossmark data \ulcorner

Citing articles: 5 View citing articles 


\title{
Operationalizing inclusive innovation: lessons from innovation platforms in livestock value chains in India and Mozambique
}

\author{
Kees Swaans $^{\mathrm{a} *}$, Birgit Boogaard ${ }^{\mathrm{b}}$, Ramkumar Bendapudi ${ }^{\mathrm{c}}$, Hailemichael Taye ${ }^{\mathrm{a}}$, \\ Saskia Hendrickx ${ }^{\mathrm{b}}$ and Laurens Klerkx ${ }^{\mathrm{d}}$ \\ ${ }^{a}$ International Livestock Research Institute (ILRI), Addis Ababa, Ethiopia; ${ }^{b}$ ILRI, Maputo, Mozambique; \\ ${ }^{c} I L R I$, Delhi, India; ${ }^{d}$ Knowledge, Technology and Innovation Group, Wageningen University, \\ Wageningen, The Netherlands
}

\begin{abstract}
Various authors have identified the potential relevance of innovation system approaches for inclusive innovation, that is, the means by which new goods and services are developed for and by the poor. However, it is still a question how best to operationalize this. Innovation platforms (IPs) represent an example of putting an inclusive innovation system approach into practice by bringing different types of stakeholders together to address issues of mutual concern and interest with a specific focus on the marginalized poor. This paper explores the formation and functioning of IPs with the aim of providing lessons on the conditions and factors that play a role in making them effective. The study shows the importance of social organization, representation, and incentives to ensure a 'true' participatory innovation process, which is based on demand and embedded in the context. Critical to this is a flexible planning process stimulating incremental change through so-called innovation bundles (i.e. combinations of technological, organizational, and institutional innovations) and reflexive learning (systematically challenging constraining factors). Furthermore, local institutions embedded in norms and values are crucial to understand people's decisions. Due to weak linkages between value chain actors, innovation brokers have a vital role in facilitating the innovation process. Overall, IPs are a promising model for inclusive innovation, but they require a careful assessment of and adjustment to the institutional context.
\end{abstract}

Keywords: innovation systems; innovation platforms; inclusive innovation; AR4D; agricultural development; agricultural systems

\section{Introduction}

Innovation and technological change can play an important role in poverty reduction, but conventional approaches have failed to deliver for the poor (Leeuwis and van den Ban 2004; Cozzens and Sutz 2014). This is most striking in the agricultural sector, the main source of livelihood for the majority of the worlds' poorest population. The structures and processes required to develop and deliver new goods and services incorporating the needs and interests of the poor are increasingly known as ‘inclusive innovation' (Foster and Heeks 2013a). Inclusive innovation approaches are a response to generic innovation system approaches which do not sufficiently consider that inclusivity of the poor in the process of innovation (e.g. the involvement of poor

*Corresponding author. Email: k.swaans@gmail.com 
community members in design and development) and inclusivity of output of innovation processes (e.g. the development, production, and delivery of goods and services that are appropriate to the needs of the poor) are essential for development (Foster and Heeks 2013b; Cozzens and Sutz 2014). Also in agriculture, this is the case: there is an increasing interest in using a 'value chain approach' to reach development objectives, but market failures often result in suboptimal performance of the chain and limited participation of the poor (Vorley, del PozoVergnes, and Barnett 2012). ${ }^{1}$ Furthermore, in agriculture, there has been for a long time a focus on transfer of technologies aimed at solving particular technological problems at the farm level (e.g. pest management), without considering that inclusive innovation requires several significant changes in the broader setting in which smallholder farms are embedded, such as land tenure arrangements, input markets, and service provision markets (Hounkonnou et al. 2012).

In recent years, innovation platforms (IPs) - spaces which allow individuals and organizations to come together to address issues of mutual concern and interest - have been promoted as a mechanism to stimulate inclusive innovation in the context of agricultural value chains (van Rooyen and Homann-Kee Tui 2009; Nederlof, Wongtschowski, and van der Lee 2011; Ayele et al. 2012). IPs are based on innovation systems thinking: a holistic and comprehensive framework for understanding innovation as emerging from a broad network of dynamically linked actors within a particular institutional context (see Lundvall 2011, for an analysis of the development of this concept and its relevance for developing countries, and Klerkx, Mierlo, and Leeuwis 2012, for an overview of evolution of this thinking in agriculture). Although various authors have identified the potential relevance of innovation system approaches for inclusive innovation, there is still a question of how best to operationalize this and how to create appropriate policies and interventions to stimulate inclusive innovation (see Foster and Heeks 2013a, 2013b). By investigating the formation and functioning of IPs in a project on pro-poor small ruminant value chains in semi-arid areas in India and Mozambique, we hope to provide some key lessons on the conditions and factors that play a role in making them effective.

This paper is organized as follows. First, a description of the conceptual framework is given in Section 2, before introducing the case study in Section 3. In Sections 4 and 5, we will present the methodology and main findings. Finally, the findings will be discussed in relation to key concepts of inclusive innovation and recommendations are derived.

\section{Conceptual framework}

\subsection{IPs and inclusive innovation}

Innovation in its broadest sense covers the activities and processes associated with the generation, distribution, and use of new knowledge, which can be technological, organizational, and institutional (Leeuwis and van den Ban 2004). In agriculture, technological innovation refers to all sorts of biotic and abiotic artefacts and practices (e.g. new seeds, animal breeds, machinery, cultivation techniques), whereas organizational and institutional elements involve novel social arrangements (e.g. new forms of labour organization, marketing arrangements, community action; and new or revised institutional set-ups, legal arrangements, and policies) (Leeuwis and van den Ban 2004; Nederlof, Wongtschowski, and van der Lee 2011).

Innovation can be stimulated by learning emerging from relevant networks of actors working together based on some mutually agreed institutional arrangements. In generic innovation literature, concepts such as strategic alliances and innovation networks have been used to indicate this process (Pittaway et al. 2004). In the agricultural sector, such multi-actor arrangements have been captured as IPs (Nederlof, Wongtschowski, and van der Lee 2011), as a way to include the poor 
more explicitly as beneficiaries and as active participants in innovation processes (FARA 2009; Nederlof, Wongtschowski, and van der Lee 2011).

The use of multi-stakeholder platforms emerged in the early 1990s in the agricultural sector, mainly for the purpose of having a space for deliberation, negotiation, and learning to solve complex natural resource management issues (Röling 1994). This concept has been broadened to bringing together stakeholders in various sectors and from different levels of the innovation system, acknowledging, and making use of the diversity in capacity (knowledge, skills, capabilities, and resources). By connecting diverse actors such as farmers, agricultural input suppliers, traders, food processors, researchers, and government officials, who regularly come together to develop a common vision and find ways to achieve their goals, IPs enable and orchestrate co-evolution between technological development and social and institutional changes (Kilelu, Klerkx, and Leeuwis 2013).

There are several key elements of IPs that can be derived from innovation systems literature (see FARA 2009; Njuki et al. 2010; Nederlof, Wongtschowski, and van der Lee 2011; Ngwenya and Hagmann 2011). We can compare these elements against those created for inclusive innovation (Foster and Heeks 2013a) in order to understand the extent to which IPs can be understood as exemplars of inclusive innovation (see Table 1).

As can be seen from Table 1, despite some differences of language and emphasis, there is a strong fit between the tenets of inclusive innovation and the key elements of IPs:

- Scope: although inclusivity is more a process than an output focus for IPs, they look to address development challenges of excluded groups, rather than orient innovation towards profit maximization.

- Innovation: again, IPs focus especially on the innovation process, whereas Foster and Heeks (2013a) look more at the nature of innovations undertaken; but the process is inclusive and participative, and thus driven by an understanding of user needs and context, as inclusive innovation requires.

- Actors: IPs concentrate on the poor as producers, but in a way they are also consumers of certain (technological) innovations; IPs emphasize the dynamics of actor involvement based on need, but generally they are about linking demand and supply, emphasizing the role of intermediaries to facilitate the platforms.

- Learning: although IPs put a stronger emphasis on a systematic and iterative process of learning through reflection, learning basically revolves around interaction, information exchange, and learning by doing as indicated by Foster and Heeks (2013a).

- Relations: while relations in IPs are orchestrated, they also emphasize the role of informal (and formal) relations and flexibility for innovation by the poor.

- Institutions: informal and formal institutions are acknowledged as important structural elements providing constraints to inclusive innovation; IPs see it as an important task to identify these with relevant actors and try to change them over time.

In short, IPs are a way of operationalizing inclusive innovation through facilitating interaction and learning among different actors, which enable reshaping of relations and institutions.

\subsection{Key issues in IP implementation}

For the implementation of an IP, it is useful to make to make a distinction between IP formation and IP functioning (see Njuki et al. 2010). IP formation refers to a phase of design and structuring of the platform, while IP functioning refers to a phase of learning and innovation through regular and iterative planning, action, and reflection, which may lead to shifts in focus and priority. Below 
Table 1. Key elements of IPs related to concepts of inclusive systems of innovation (after Foster and Heeks 2013a).

\begin{tabular}{|c|c|c|}
\hline & Inclusive systems of innovation & IPs \\
\hline Scope & Development as socio-economic inclusion & $\begin{array}{l}\text { Bring relevant actors together to address a } \\
\text { (development) issue of common interest, } \\
\text { with a specific focus on marginalized } \\
\text { groups }\end{array}$ \\
\hline Innovation & $\begin{array}{l}\text { Incremental innovation with a focus on } \\
\text { diffusion processes (local needs oriented, } \\
\text { demand- and context-driven, non-technical } \\
\text { innovation, reverse innovation) }\end{array}$ & $\begin{array}{l}\text { Stimulate demand- and context-driven } \\
\text { innovation (technological, organisational, } \\
\text { and institutional) through joint problem } \\
\text { solving, making use of diversity among IP } \\
\text { members }\end{array}$ \\
\hline Actors & $\begin{array}{l}\text { Main focus on low-income producers and/or } \\
\text { consumers; non-traditional, less formal, } \\
\text { demand-side innovators, chain of } \\
\text { intermediaries, linking supply and demand }\end{array}$ & $\begin{array}{l}\text { Main focus on poor producers; relevant actors } \\
\text { are invited based on scoping and analysis; } \\
\text { membership not fixed, but dynamic, based } \\
\text { on need; usually intermediaries facilitate } \\
\text { and coordinate the platform }\end{array}$ \\
\hline Learning & $\begin{array}{l}\text { Contextualized (supply, demand, other); } \\
\text { learning by interacting and using and doing } \\
\text { (learning about diffusion and use; learning } \\
\text { about wider social processes including non- } \\
\text { instrumental processes; survival and utility- } \\
\text { maximization as guides) }\end{array}$ & $\begin{array}{l}\text { Contextualized learning through } \\
\text { communication and information exchange } \\
\text { among actors and by trying out; learning } \\
\text { based on systematic and iterative process of } \\
\text { action, monitoring, reflection, and } \\
\text { adaptation }\end{array}$ \\
\hline Relations & $\begin{array}{l}\text { Necessity (but also limitation) of informal, } \\
\text { loose, but socialized relations }\end{array}$ & $\begin{array}{l}\text { Linkages established through interactions } \\
\text { between members of the platform and other } \\
\text { informal/formal actors necessary to achieve } \\
\text { the overall objective; interactions are } \\
\text { usually facilitated and coordinated }\end{array}$ \\
\hline Institutions & $\begin{array}{l}\text { Complex institutional terrain of informal and } \\
\text { formal; indirect impact of core, formal } \\
\text { institutional forces; importance (including } \\
\text { potential negative impact) of informal } \\
\text { institutions at local level }\end{array}$ & $\begin{array}{l}\text { Key institutional constraints and } \\
\text { opportunities are jointly identified and } \\
\text { addressed; institutions can be informal and } \\
\text { formal }\end{array}$ \\
\hline
\end{tabular}

we describe these two phases in more detail, in order to derive key issues for analysing IP formation and functioning.

\subsubsection{IP formation}

Wennink and Ochola (2011) distinguish three steps in the formation of IPs: scoping, analysis, and planning. Every step has some key aspects that need to be addressed. 'Scoping' refers to the initial effort to narrow down the platform's topic or focus, and to better understand it, along with the context where the platform is to be inserted; this may affect the level of operation (local, national, etc.), the type of stakeholders, and the organization and governance of the platform. 'Analysis' contributes to identification of the knowledge, skills, and interests including capacity needs, and joint analysis of problems and opportunities related to the topic of the platform. It often includes a stakeholder or network analysis to map the linkages between the different actors in the agricultural innovation system to make sure that all key stakeholders - including the poor and women - are invited (see also FARA 2009). Finally, 'Planning' is related to a further narrowing down of main points raised during the analysis, and agreement on who must do what and when and the development of an action plan (FARA 2009; Nederlof, Wongtschowski, and van der Lee 2011); this also refers to decisions 
Table 2. Key parameters for analysing IP formation and functioning.

\begin{tabular}{ll}
\hline \multicolumn{1}{c}{ Key parameters } \\
\hline IP formation & Inclusion and representation \\
& Focus, tasks, and roles \\
& Identification of constraints and opportunities \\
& Inventory of knowledge, skills, and interests \\
& Organizational structure and governance \\
& Resources \\
IP functioning & Participation, commitment, and ownership \\
& Information exchange and communication \\
& Use of diversity in knowledge, skills, and interests \\
& Systematic planning, action, and reflection \\
& Capacity building \\
& Facilitation and management \\
& Resource mobilization \\
\hline
\end{tabular}

regarding the modalities of the platform, how exactly and by whom it will be governed, and the use of resources.

\subsubsection{IP functioning}

After rules and modalities for the platform have been set, a routine of regular IP meetings with feedback of agreed-upon actions becomes established (see Njuki et al. 2010; Nederlof, Wongtschowski, and van der Lee 2011); there are a number of issues that are essential for smooth operation of a platform. First, it is important to ensure that members of the platform actively participate, are committed, and feel a sense of ownership of the process. An effective and efficient process of information sharing and communication needs to be in place, taking into account the diversity in knowledge, skills, and interests of actors. To stimulate a culture of continuous learning, an iterative process of planning, action, and reflection has to be established (Nederlof, Wongtschowski, and van der Lee 2011), which is further enhanced through human and institutional capacity building. Facilitation and management have a critical role to play (Ngwenya and Hagmann 2011), often involving a transition from an external-led initiative to a self-organized platform. Resource mobilization, both in terms of human, physical, and financial resources and in terms of endorsement and support, will be crucial to sustain the process beyond the lifetime of the project.

Key parameters for analysing IP formation and functioning are summarized in Table 2.

\section{The imGoats project: a case description}

The imGoats project was implemented from January 2011 to June 2013 (30 months) with the aim to transform goat production and marketing in semi-arid areas of India and Mozambique to a sound and profitable enterprise and model that would tap into a growing market. The main target beneficiaries of the project were poor goat keepers, both men and women. The overall project was managed by the International Livestock Research Institute (ILRI) and implemented by Bharatiya Agro Industry Foundation (BAIF) and the Cooperative for Assistance and Relief Everywhere (CARE).

The specific project area in India was Rajasthan State with 2600 target households in Jhadol and Sarada blocks of Udaipur district. For logistical reasons, the number of goat keeper groups 
participating in the IP was limited to those in the radius of 10-12 km from Jhadol town (IP meeting location). This resulted in 18 project villages being part of the platform, covering about 1000 households ( 88 groups), with 10-15 families per group. In Mozambique, the project targeted 500 households in Inhassoro district of Inhambane Province; this represented about 3800 direct beneficiaries in 18 villages. Goat keepers were organized in 23 producer groups. Key characteristics of the project sites are described in Table 3.

IPs were used to facilitate communication and collaboration and promote joint action and innovation among the actors along the value chain. They followed an iterative process and met - after an intensive formation process - every two to three months to discuss and implement opportunities to improve markets, production and related policy issues (following van Rooyen and Homann-Kee Tui 2009). Figures 1 and 2 provide an overview for, respectively, India and Mozambique of the key issues discussed or decided in IP meetings and the main actions resulting from those in terms of activities undertaken by IP members, research for and on the IP, and capacity building to support initiated activities.

In both countries, producer groups met regularly with the community animal health workers (CAHWs) and there was an increased interaction with other value chain actors (VC actors) through the IPs. Improved linkages between key actors led to various technological, organizational, and institutional innovations (see Table 4).

Table 3. Key characteristics of the IP project sites.

\begin{tabular}{|c|c|c|}
\hline Topic & Udaipur district, India & Inhassoro district, Mozambique \\
\hline Population density & $196 / \mathrm{km}^{2}$ & $11 / \mathrm{km}^{2}$ \\
\hline IP target households & 1000 & 500 \\
\hline Literacy levels & $59 \%$ & $\begin{array}{l}51 \% \text { (for Mozambique; no information } \\
\text { on province or district) }\end{array}$ \\
\hline Average annual rainfall & $600 \mathrm{~mm}$ & $600-800 \mathrm{~mm}$ \\
\hline Livelihoods & $\begin{array}{l}\text { Small land and livestock holdings } \\
\text { (subsistence agriculture); wage } \\
\text { labour important source of income }\end{array}$ & $\begin{array}{l}\text { Small land and livestock holdings } \\
\text { (subsistence agriculture); crop } \\
\text { production main occupation; cattle } \\
\text { numbers very low }\end{array}$ \\
\hline Main crops & $\begin{array}{l}\text { Maize, wheat, barley, chickpea, rape, } \\
\text { and mustard }\end{array}$ & $\begin{array}{l}\text { Maize, groundnuts, beans, cassava, and } \\
\text { millet }\end{array}$ \\
\hline Average goat herd size & $6.2($ range $1-16)$ & $8.4($ range $1-30)$ \\
\hline Marketing practices & $\begin{array}{l}\text { During main festive period (October to } \\
\text { December) and ad hoc throughout } \\
\text { the year to meet household demands }\end{array}$ & $\begin{array}{l}\text { During festive period (December) and } \\
\text { ad hoc throughout the year to meet } \\
\text { household demands }\end{array}$ \\
\hline Nearest goat market & 50 km (Udaipur) & 200 km (Massinga) \\
\hline $\begin{array}{l}\text { Main goat value chain } \\
\text { constraints }\end{array}$ & $\begin{array}{l}\text { Inferior male breeding goats; limited } \\
\text { access to animal health services; low } \\
\text { number of goats available for sale; } \\
\text { limited knowledge about improved } \\
\text { husbandry practices }\end{array}$ & $\begin{array}{l}\text { Low number of goats; limited access to } \\
\text { animal health services; lack of } \\
\text { organization of producers; lack of } \\
\text { infrastructure; limited knowledge } \\
\text { about improved husbandry practices }\end{array}$ \\
\hline Main value chain actors & $\begin{array}{l}\text { Producers; community animal health } \\
\text { workers (CAHWs); local traders/ } \\
\text { butchers; long distance traders; local } \\
\text { pharmacist; Animal Husbandry } \\
\text { Department; BAIF; research (ILRI, } \\
\text { Veterinary College) }\end{array}$ & $\begin{array}{l}\text { Producers; CAHWs; local traders/ } \\
\text { butchers; local retailer; District and } \\
\text { Provincial Veterinary Services; } \\
\text { CARE; research (ILRI) }\end{array}$ \\
\hline
\end{tabular}

Source: internal documents. 


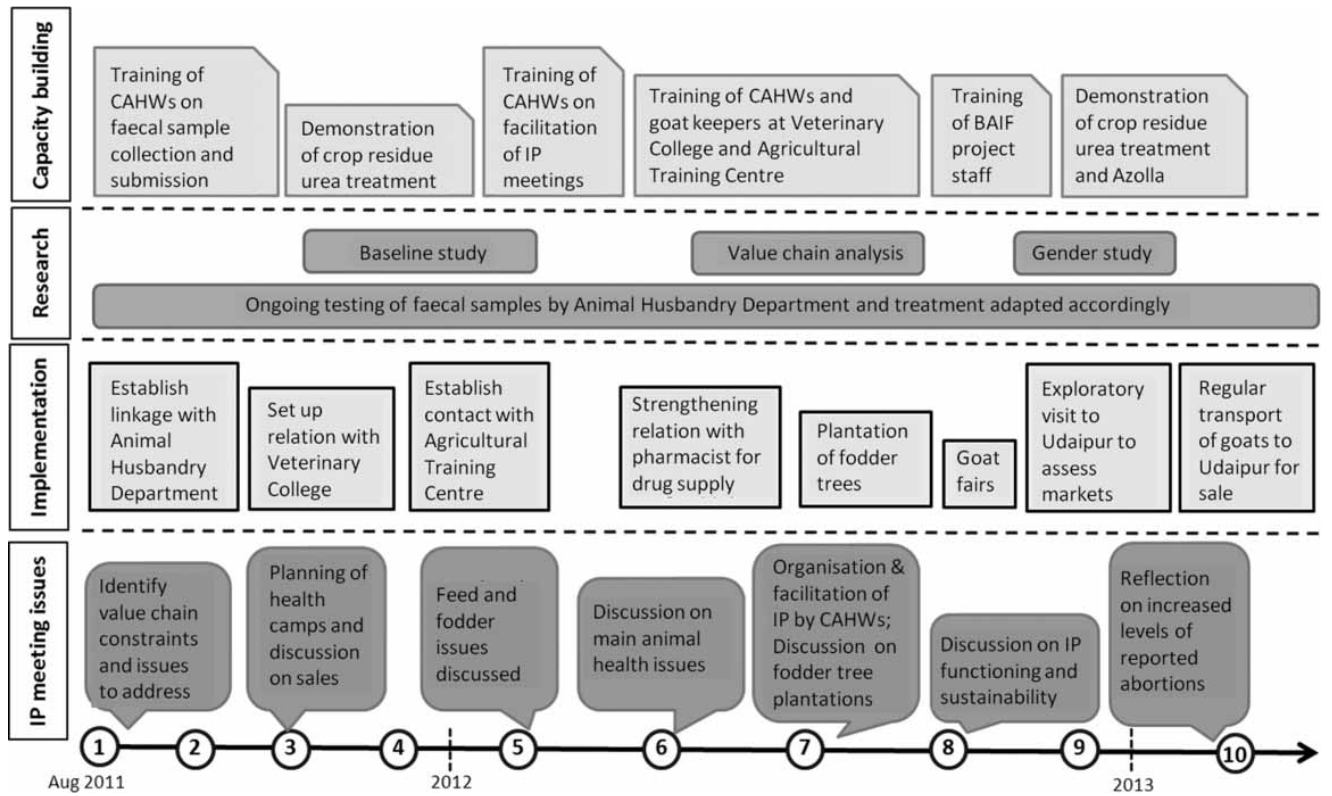

Figure 1. Timeline of IP meetings (O), key issues discussed and resulting activities (implementation, research, and capacity building) in Udaipur district, India.

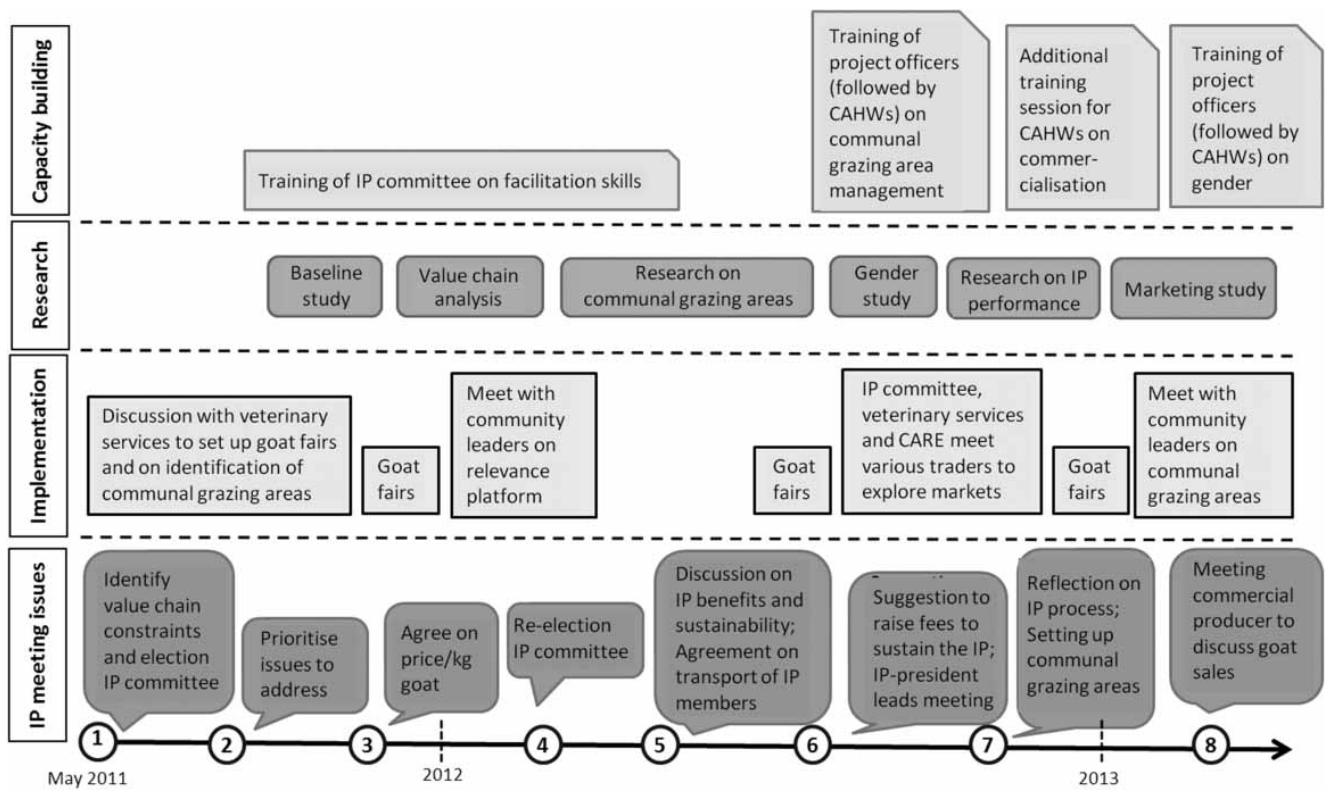

Figure 2. Timeline of IP meetings (O), key issues discussed and resulting activities (implementation, research, and capacity building) in Inhassoro district, Mozambique. 
Table 4. Main innovations in goat value chains as result of IPs in the project areas.

\begin{tabular}{lll}
\hline Innovation & \multicolumn{1}{c}{ Udaipur district, India } & \multicolumn{1}{c}{ Inhassoro district, Mozambique } \\
\hline Technological & Animal health service delivery by & Improved goat husbandry practices (watering, \\
& CAHWs & feeding, etc.) \\
& Alternative feeds and new feeding & Improved goat shelters based on local \\
techniques & resources \\
& Better breeding practices (e.g. improved & Animal health service delivery by CAHWs \\
& male goats available; castrating inferior & Guidelines/training in sustainable communal \\
& male goats) & grazing management based on local \\
& situation & \\
Organizational & Aggregation of animals by CAHWs for & Aggregation of animals by CAHWs for \\
& selling & selling \\
& Organization of goat fairs and exploring & Organization of goat fairs and exploring new \\
& new markets & markets \\
& Organization of health camps for & Collective management of communal grazing \\
vaccination & areas \\
Institutional & IP for actors along the value chain to improve \\
& gor actors along the value chain to & goat production and marketing \\
& improve goat production and marketing & Introduction of weighing scales and pre- \\
& New ways of collaboration between & established live weight price to guarantee a \\
& CAHWs and veterinary services for & fair price \\
& faecal sample testing & Enforcing of existing legislation of communal \\
& grazing areas by the district government, \\
& including demarcation of areas, and \\
& establishment of management associations
\end{tabular}

The mix of innovations had positive effects on goat management practices, production, and sales. Some key results were:

- In India, goat mortality rates dropped from $30-40 \%$ in 2011 to around $10 \%$ in March 2013. In Mozambique, the producers also reported a sharp decrease in mortality figures.

- The number of goats increased by at least one or two animals per household in India. There was also anecdotal evidence of increased herd size among producers in Mozambique, but as data collection on production parameters was a challenge, there is no strong evidence for a systematic change across households.

- Data from India further showed that producers were selling more animals: from one animal on average in 2011 to two in 2013, and they received higher prices as a result of increased weight and castrating the males. In Mozambique, producers had also been selling more animals to distant markets, due to a lack of local demand for goats.

\section{Methodology}

The research design is a comparative case study based on the imGoats project. A case study allows for an in-depth understanding of the dynamics in the innovation process and multi-stakeholder collaboration (Yin 2003). The study involved participatory observation by two of the authors (RB and $\mathrm{BB}$ ). Data, mainly qualitative, were collected throughout the project duration (from 2011 to 2013) and the research reported in this paper is based on the analysis of 
methods used within the context of the IPs themselves. By analysing the innovation process in each case, more insight was gained into the factors and conditions that make IPs effective. The comparison of platforms in two very different settings further enhances the analytical strength of the study.

Various methods were used to analyse IP formation and functioning:

- Review of project documents to understand the context in which the IPs happened.

- IP meeting reports that included: issues discussed and decisions taken, feedback from previous activities and participant lists.

- Recording project progress by mapping behavioural change among VC actors (in terms of relations, practices, and activities).

- Project team reflection exercises to discuss progress made and underlying reasons, held half-way and at the end of the project.

Qualitative data were subjected to thematic content analysis based on the key elements of the analytical framework. To enhance validity of the data, triangulation of various sources and methods was applied. Data analyses and preliminary findings were discussed in-depth amongst the authors. In the course of theorizing, challenging, and making sense of the data observed in the two sites, we have endeavoured to reveal the mechanisms, factors, and conditions that underlie the performance of the IPs.

\section{Findings}

\subsection{IP formation}

Drawing on the two cases, this section explains the various aspects to consider during IP formation. These aspects (as per Table 2) are: inclusion and representation; a clear focus, tasks, and roles; the identification of constraints and opportunities; an inventory of knowledge, attitudes and skills; organizational structure and governance; and resources.

\subsubsection{Inclusion and representation}

Critical to the IP formation process were the inclusion of the poor and the representation of key actors along the chain. The VC actors in India and Mozambique were identified by respectively BAIF and CARE based on previous experience and consultation. Actors were categorized as producers (goatkeepers and CAHWs), input and service providers (CAHWs, retailer/pharmacist, and veterinary services), post-production actors (mainly traders), and enabling agencies (community leaders, government agencies, CARE/BAIF, and ILRI) (see also Table 3). Membership was flexible, so that new actors could become involved (or existing members leave), based on need.

In India, all participating households in the IP (about 1200; 9\% female headed; organized in 88 groups) belonged to Scheduled Tribes, a marginalized group living below the poverty line. Traders were identified based on their interest and through (informal) leadership among traders. In Mozambique, producers (524; 38\% women; organized in 23 groups) were selected based on having goats and who had an interest in a goat production and marketing project. However, there were few local traders and private investors in Inhambane Province, making the platform dependent on a small group of actors.

In both countries, there was a clear mechanism for representation of the producer groups in the platform. In India, producer groups were represented by two goat keepers nominated by community members in each village, while CAHWs (serving 100 households, or about 
7-10 groups, each) participated as well. In Mozambique, each producer group was asked to elect a representative and a CAHW, which was done in a democratic and participatory way.

\subsubsection{Focus, roles, and tasks}

IPs were found to be the most effective when they had a clear focus with identified roles/tasks for their members. The vision and objective were conceptualized by the project partners at the start of the project and shared at the first IP meeting. However, it was initially difficult for goat producers and other community representatives to think beyond 'production' and to focus on the whole value chain with a commodity focus. During the baseline survey in Mozambique - for logistical reasons initiated after the introduction of the IPs - it became apparent that the main occupation in the area was the cultivation of crops for home consumption with goat husbandry as a low input/ low output side occupation. The commercialization of goats not only required a mental shift among producers and community members, but also a better understanding among the project partners and other actors of the role that goats play in people's livelihoods and farming systems to avoid negative effects.

The lack of common vision building in both countries may also explain that while actors had a clear understanding of their 'position' in the value chain, their roles and tasks (how each actor can contribute to a growing market with win-win situations) were insufficiently explored. For example, the role of traders and government agencies was rather passive/supportive, instead of taking a proactive role, for example, by providing information on markets and consumer preferences and creating incentives for access to inputs and services.

\subsubsection{Identification of constraints and opportunities}

The identification of constraints and opportunities helped to narrow down the focus of the platform. In both countries, constraint and opportunity identification was done in a participatory manner facilitated by the project partners. The issues identified were related to production (animal health, husbandry practices, and infrastructure) and marketing (through organization of producers) and were perceived as closely interlinked; in later stages of the project, other constraints emerged (e.g. lack of feed and water and lack of cash among traders). A drawback was that - partly due to the lack of common vision building and the postponement of the baseline survey (including the value chain analysis) - most of the identified problems and opportunities focused on the producers or production aspects, without further exploring challenges faced along the value chain and among other VC actors, reducing their subsequent interest in the process.

\subsubsection{Identification of knowledge, attitudes, and skills}

As knowledge, attitudes, and skills have implications for planning and innovation processes, it was important to make an inventory of knowledge and skills among actors across the chain at the start of the project. The initial assessment was based on previous experiences of BAIF/CARE; this was later supplemented with information from the baseline study, providing more insights into the context and specific needs of producers. In both countries, producers had limited knowledge and skills of goat husbandry practices and had had minimal training on production and marketing, which made it challenging to move from irregular ad hoc emergency sales to a pattern of regular sales. Moreover, no formal ex ante assessment was held or planned on knowledge, skills, and capacities among other VC actors. This made 
it difficult to identify opportunities for addressing constraints from within the system and which could have enhanced a feeling of mutual dependency and ownership.

\subsubsection{Organizational structure and governance}

In both countries, IPs were newly established. BAIF/CARE and ILRI took the lead in the initial stages in facilitating and coordinating the IP meetings, but mechanisms were put in place to hand this over to local actors to sustain the innovation process after the project would end. In India, it was envisaged that CAHWs would take over this role; in Mozambique, a committee of four IP members was elected. The frequency of IP meetings was set by the IP members at an interval of every two months. In India, the meeting was at a fixed location, while in Mozambique the location varied. However, as regards ownership, it was a challenge to develop this among local actors who did not have experience with IPs, while documented experience on how to facilitate self-organization in IPs was limited.

\subsubsection{Resources}

Resources for the platform were provided by project funding through BAIF and CARE, which included mainly human resources, but also expenses incurred on transportation and refreshments. In Mozambique, participants were collected by car as locations were spread out. It was the intention to stop providing transport after the first meeting, but in practice, this decision was only taken in the fifth meeting after a discussion on sustainability of the platform among the IP members.

The key findings of the IP formation process are summarized in Box 1.

Box 1. Summary of the IP formation process

- The IP formation process was inclusive: all VC actors were represented; mechanisms were put in place for representation of producer groups.

- The vision and objective were conceptualized by the project partners; potential tasks/ roles of some VC actors in the innovation process were insufficiently explored.

- Problem identification was participatory with a focus on production and marketing; key constraints were closely interlinked.

- Assessment of knowledge/skills among producers and CAHWs was thoroughly explored, but no assessment was planned among other $\mathrm{VC}$ actors.

- Project partners took the lead in facilitation and management of the IPs; mechanisms were established to hand this over to local actors.

- Resources were provided through project funding.

\subsection{IP functioning}

After the rules and modalities of the platform have been set, a routine of regular IP meetings with feedback on agreed actions becomes established. Key processes that determine IP functioning are (as per Table 2): participation, commitment, and ownership; information sharing and communication; use of the diversity of knowledge and skills; a systematic process of planning, action, and reflection; capacity building; facilitation and management; and resource mobilization. In this section, we assess how these processes were designed and applied in the case studies. 


\subsubsection{Participation, commitment, and ownership}

For a well-functioning IP, the members need to participate actively, be committed to a common cause, and perceive the process as their own. Project reports showed that there was a continuous effort to keep different VC actors involved. In both countries, producers were well represented in the meetings, but there was also large inconsistency in terms of who participated. In India, other activities and events (onset of cropping season, religious festivals) interfered, while in Mozambique, the change in meeting locations played a role. Moreover, in Mozambique, the average number of producers dropped after the fifth meeting, most likely due to a combination of the decision to stop providing transport and unclear incentives for participants; when in the eighth IP meeting, a private investor was involved with potential to buy goats, the number of producers - coming to the meeting by their own transport - increased again. CAHWs and government officials had been active throughout the process; BAIF and CARE worked closely with the CAHWs as service provider and link between the platforms and producer groups, and maintained regular contact with the government agencies.

The involvement of traders and women was, however, problematic. In India, the traders who participated in the first IP meeting made it clear that they would be available in case there are goats to be sold but they did not see the need for their participation in every meeting. Also in Mozambique, traders were initially interested and stimulated the organization of producers, which allowed them to buy an agreed amount of goats at certain dates. However, after the first few goat fairs, their interest faded as demand for goats was lower than anticipated. Also participation of women in the IP meetings was low. Women were mainly found in the producer groups and not among other $\mathrm{VC}$ actors. In India, low participation was generally due to the local cultural setting whereby traditionally women are not allowed to leave their community. In Mozambique, initially women participated, but the number decreased after a few IP meetings. This may have been related to an increased interest of community leaders to participate, possibly replacing the female participants as representative for the community. The strong focus on commercialization and marketing - which are considered men's tasks - and the burden of domestic chores may also have played a role.

\subsubsection{Communication and information exchange}

To enhance innovation, effective and efficient communication and knowledge sharing are important, not only between IP members but also beyond the platform. In both countries, information on goat management practices and marketing, constraints, and opportunities was well communicated and shared among VC actors within the platform. CAHWs also shared information with producers during regular group meetings, but there was limited input from the groups regarding issues to be discussed at the platform. As a result of the interventions, information flows between producers and government were strengthened, although the information flow with traders remained rather difficult (slightly better in India compared to Mozambique).

\subsubsection{Use of diversity in knowledge and skills}

There were several specific actions throughout the innovation process that can be related to the use of knowledge/skills of different VC actors (although these were not assessed explicitly ex ante). In India, IP meetings were used to tap into the knowledge from the veterinarian to act on issues that emerged during the meeting; it also exposed CAHWs to a systematic approach to faecal sample testing to identify worm-loads before taking up de-worming. Apart from this, information from the pharmacist was also used to understand what medicines were locally 
available and what could be ordered in bulk in case the CAHWs wanted to make the purchases collectively. Also in terms of marketing, awareness among the producers and CAHWs increased because of interactions with traders (even if limited) and while preparing action plans to conduct goat fairs or organizing exposure-cum-sale visits to markets in the nearest town. In the case of Mozambique, producers' knowledge and practices on grazing areas were assessed for the development of communal pasture, while subsequently local government, community leaders, and CAHWs provided knowledge for the identification and legislation of communal pasture areas. In addition, five model farmers were identified to share their experiences to other producers, for example, with improved shelters and the provision of water to goats on a regular basis. In general, though, there was less attention to the diversity in knowledge and skills within each group of VC actors and how these could have been exploited.

\subsubsection{Systematic planning, action, and reflection}

In both countries, IP meetings were characterized by a systematic and iterative process of planning, action, reflection, and adaptation. But while some innovation processes were highly predictable, others were unforeseen and unexpected (see Boogaard et al. 2013, for Mozambique). For example, in both countries, access to animal health services was addressed through technological and organizational innovations. These interventions were relatively straightforward and required limited changes in existing extension and training models.

Improving market access was more complicated and included a combination of organizational (aggregation of animals, organization of goat fairs) and institutional elements (the introduction of weighing scales and a pre-established live weight price to guarantee a fair price). In both countries, the organization of goat markets was tried with mixed results and alternative sales strategies were explored (in India, producers started transporting animals to Udaipur and in Mozambique, a private investor and a slaughterhouse were approached). Even less predictable and unforeseen was the development of communal grazing areas in Mozambique. Most goats in Inhassoro District were tethered even though grazing areas were present in the district. The IP members identified the need for communal grazing areas in an IP meeting. The innovation required an integrated package of technological (new management techniques), organizational (collective action between smallholders, community leaders, CAHWs, and local government), and institutional interventions (legalisation of the areas by the district government, including demarcation of the area, and the establishment of associations in the communities which were legally responsible for the areas). Planning in this case was more flexible and adapted in response to daily activities of project staff and IP members.

In the case of Mozambique, there were also regular reflections with members of the platform on the IP process itself; although increased insight did not lead to drastic changes in terms of goals and strategy, some changes were made in terms of the design (e.g. it was decided to stop providing transport and choose a central location for the meeting after the fifth meeting).

\subsubsection{Capacity building}

Capacity building was one of the core elements to further improve the innovation process. Capacity building was based on existing experiences from BAIF and CARE, which were further informed by the baseline surveys and issues that emerged during the IP process. Gaps in knowledge were addressed through specific training sessions and exchange and 
exposure visits with support from government training institutes and project partners. In both countries, the focus was mainly on producers and CAHWs. In India, sessions were provided on animal health and alternative feeds and feeding techniques, whereas in Mozambique, training concentrated on the management of goats, communal grazing area management, and commercialization of goats. Exchange visits took place between producer groups, while some of the IP members visited potential new traders and markets. Besides the conventional training and exchange/exposure visits, also the exchange of information between members of the platform itself was seen as an important source for learning. This was often informed by feedback of research results, for example, on baseline surveys and studies on specific topics (e.g. on communal grazing areas); crucial in this respect was the timely feedback and the development of easy understandable flyers with key findings and graphics.

CAHWs (India) and IP committee members (Mozambique) were further trained in the facilitation of IPs, while staff from BAIF/CARE received additional sessions on goat management practices and/or gender. What was lacking though was the identification of training needs among other actors. This may have negatively affected the innovation process. For example, in the case of Mozambique, it was assumed that traders had interest in buying goats and a certain degree of entrepreneurial skills. A marketing study in Mozambique revealed, however, that local traders were largely unaware of consumer preferences and behaviour.

\subsubsection{Facilitation and management}

The management process within the IP can be seen as the role of innovation brokers, defined as the persons and organizations that catalyse innovation by bringing actors together and facilitating their interaction (Klerkx, Hall, and Leeuwis 2009). BAIF/CARE and ILRI were responsible for the implementation and facilitation of the IP. However, in addition to the main purpose of innovation brokers - to create linkages and facilitate multi-actor interaction in innovation - they also conducted activities related to strategic networking, technical backstopping, mediation, advocacy, capacity building, and reporting. ILRI postdoctoral researchers played a significant role in terms of research and documentation. The research element was new to BAIF and CARE and played an important role in improved understanding of the local context and in identification of constraints and solutions.

The multiple roles of BAIF/CARE and ILRI within the project revealed their active dynamism that allowed them to adapt to new challenges. IP facilitation and management were gradually handed over to IP members, but this needed a lot of guidance. For these reasons, most of the decisions related to the design of the platform were influenced by former experiences of BAIF/ CARE and ILRI.

\subsubsection{Resource mobilization}

Resource mobilization was a strategic concern for the IP functioning and its continuity. IP facilitation and management were highly resource intensive, especially in terms of human resources. It is important to emphasize that the IP was a process, with regular meetings and follow-up; it also included extra efforts to obtain necessary endorsement and support from community leaders and producer groups, while strategic linkages were made with government agencies. 
The key findings on IP functioning are summarized in Box 2.

Box 2. Summary of IP functioning

- Participation varied across the VC actors; traders and women were difficult to involve in the innovation process.

- Information flow from platform to producer groups was good, but weak the other way around; CAHWs formed an important link with producers.

- The IP tapped into the knowledge/skills of some VC actors, especially in India; however, diversity in knowledge/skills within each actor group remained largely unexplored.

- Problem solving followed a systematic innovation process, including technological, organizational, and institutional elements; where some interventions were highly predictable, others were not and required flexible planning; in Mozambique, there was a stronger reflection on the IP as an institutional innovation itself.

- Capacity building through training and exposure/exchange visits was important, but the main focus was on producers and CAHWs; IP meetings were also recognized as a form of capacity building through systematic reflection.

- Innovation brokering included multiple diverse tasks; facilitation was gradually handed over to local actors, but project partners continued to play an important role.

- IPs were (human) resource intensive; including extra efforts to get endorsement and support from community leaders and producer groups, and creating strategic linkages with government agencies.

\section{Discussion}

The study showed that IPs can enhance production and marketing by establishing linkages between smallholders and other actors in the value chain. Increased interaction between IP members led to innovations including the introduction and adaptation of goat management practices based on local resources; new forms of organizing producers, production, and marketing; and novel ways of working together with other VC actors. However, the changes in terms of productivity through technical and service delivery interventions and sales were clearer in the case of India, compared to the case from Mozambique. To gain more insight into how innovation system approaches can be made more effective for the poor and enhance inclusive innovation, we analysed the implementation of IPs in terms of IP formation and functioning; here we would like to discuss the main findings of the case study in relation to key concepts of inclusive innovation (i.e. actors, innovation, learning, relations, institutions, and scope; see Table 5).

When we look at the type of actors that were or need to be involved in these instances of inclusive innovation, there are a few key issues worth mentioning. First of all, there is the issue of inclusion and representation. Rules and recruitment of participants may unintentionally lead to exclusion, rather than inclusion (see Swaans et al. 2008). For example, in India, IP meetings were held in Jhadol town, making it difficult for women to attend for cultural reasons. In Mozambique, cost and availability of transport to the meeting venue were a constraining factor. The design and implementation of IPs need to be adapted to and negotiated with the intended beneficiaries. Furthermore, the study showed that especially in Mozambique, the value chain was dependent on a limited set of actors (e.g. in the case of traders), which made 
Table 5. Key issues in IP formation and functioning derived from the case study.

Key issues in IP formation and functioning

Actors Rules and regulations (i.e. design) of the platform need to be adapted to include the poor Representation of different types of $\mathrm{VC}$ actors is critical

Due to weak linkages between VC actors, intermediaries play a critical role

Innovation Importance of incentives to ensure demand-driven and contextualized innovation process

Flexible approach to support incremental change and bundles of innovation (technological, social, and institutional)

Social organization of producers important for learning and demand articulation

Learning Learning through interaction and learning by doing; (technical) learning through conventional training, demonstration, and exposure

Reflexive (transformative) learning by challenging (underlying) critical constraints; important role for research

Learning/alignment of $\mathrm{VC}$ actors to work towards a common cause

Relations Important to nurture socialized informal (flexible) relations to foster innovation

Necessary to ensure some consistency in (more formal) relations to reduce risk and uncertainty

Innovation brokers are critical to link producers to the IP and to establish linkages between VC actors (there may be different intermediaries)

Institutions Formal institutions (and change thereof) are important to support the innovation process

Informal institutions such as trust and norms and values are important for people's behaviour, and may require specific methods to address them

Scope Actors need to feel mutually dependent before engaging them in a process

Take into account diversity among main beneficiaries when deciding on main focus

it highly vulnerable. The weak linkages between various actors of the value chain made the role of an intermediary for innovation brokering at the initial stages essential.

Innovation in the platforms was strongly demand- and context-driven, but it required a flexible planning process that was able to cater for both predictable and unexpected and unforeseen developments. Like many inclusive innovations, these were not necessarily new, but they were new in the context. Technological innovations were important and made a big difference (e.g. animal treatment, new management practices); but critical to their success was the extent to which these were nurtured and aligned with changes in ways of organization (producer groups, communal grazing areas, health camps, and fairs) and institutions (legislation, rules) (see also Kilelu, Klerkx, and Leeuwis 2013). Organizational innovation was especially important at the producer level; not only to reach economy of scale (through aggregation of animals), but also to stimulate learning and for better demand articulation. A key factor for innovation is the issue of incentives; although this may have been clear for producers, it was less clear for traders/butchers, and shows the importance of the development of business models among the actors in the chain (following Ngwenya and Hagmann 2011).

Learning is critical to any innovation process. Besides the importance of learning through interaction and learning by doing, there were several other types of learning that were important for these inclusive innovations. As knowledge among producers was very limited, conventional learning through training played an important role, including learning through exposure and exchange visits. A form of learning not often mentioned, and which played an important role in the IPs, is reflexive (or transformative) learning (van Mierlo, Arkesteijn, and Leeuwis 2010). Reflexive learning refers to the critical reflection on internal and external factors that constrain people's lives through a systematic process of action and reflection; in the case of the IPs in this study one can think of an improved understanding of the factors that played a role in the marketing of goats, and which helped VC actors to develop new strategies. The study also showed that research, e.g. through value chain analysis and marketing studies, can contribute 
in revealing these critical factors. Furthermore, learning was important across the chain to ensure that actors were aligned and worked towards a common cause.

In terms of relations, IPs need to be connected to a system that allows for information exchange, experimentation, and learning among producers, for example, through producer groups (see also Ayele et al. 2012). In the two case studies, communication and information exchange among actors within the platforms were well organized, but it proved more difficult to extend this beyond the platform, especially the producer groups. The role of CAHWs as a 'broker' or 'linkage' between the IP and the producer groups was critical. In Mozambique, also model farmers played an important role in mobilizing producers. Although informal socialized relations are important to keep the platform dynamic and able to respond to changes, some form of consistency is desirable to develop reliable relations to reduce uncertainty and risk. Hence, while the study showed the importance of intermediaries to link producers to the platform (e.g. through CAHWs), it also showed the importance of innovation brokers to establish relations with other VC actors (confirming findings by Klerkx, Hall, and Leeuwis 2009; Szogs, Cummings, and Chaminade 2011; Foster and Heeks 2013a).

This brings us to the issues of institutions. Formal institutions were important to support the innovation process, but at least as important were the informal (local) institutions, that is, norms and values on gender and the lack of trust between producers and traders. A group-based approach provides the opportunity to get to know each other, build trust, and stimulate learning; it provides the opportunity to challenge underlying values and relations between stakeholders. However, this may work better in homogeneous settings whereby people feel free to express themselves, than in heterogeneous groups such as an IP; this may particularly be difficult in a value chain context when transactions and competition play an important role. Hence, IPs may need to go along with other forms of interaction at the local level. Also the involvement of champions as role models and support from local leaders was crucial in this respect. To address the way different $\mathrm{VC}$ actors work together, requires high-quality facilitation and identification of win-win situations.

Finally, considering the overall focus on socio-economic development, IPs can provide an important mechanism for inclusive innovation but only when actors feel that they are dependent on each other to address certain issues. Moreover, a value chain approach may not be appropriate in every context. In Mozambique, the value chain was very weak or almost non-existent; goats had multiple functions in the households and not everyone - especially women - may have been interested in the commercialization of goats. The IPs did not fully capture this. Under such conditions, alternatives such as a stronger focus on production or diversification of livelihood strategies need to be considered (see Amankwah et al. 2012).

\section{Conclusion}

From our study, a number of lessons can be drawn as regards using an IP approach to operationalize inclusive innovation. The study shows that social organization, representation, and incentives are important to ensure a 'true' participatory and inclusive innovation process. This requires flexible planning that stimulates incremental change through a mix of technological, organizational, and institutional innovations and (reflexive) learning. Furthermore, a better understanding of local institutions embedded in norms and values is crucial to change people's practices and decisions. Due to the - often - weak linkages among actors in the innovation system, brokers have a vital role to play to facilitate these inclusive innovation processes.

Some key recommendations are: (1) a diagnostic study, including value chain and gender analysis during the inception phase of projects is important to gain a better understanding of the context; (2) the design of IPs and their implementation needs to be adapted to and negotiated 
with the intended beneficiaries; (3) facilitation by project partners in the initial stages of the IPs may be necessary but handing over to local actors is crucial for continuity and requires time, capacity, and respect from other members of the platform; (4) the complexity of the innovation process requires flexibility from platform members in terms of planning with attention to technological, organizational, and institutional elements; and (5) government decision-makers need to be engaged in the process when appropriate to ensure that innovations are embedded in government strategies and policies.

Overall, IPs are a promising model for operationalizing inclusive innovation, but this requires a careful assessment of and adjustment to the local institutional context. Here also lies a main issue in terms of the scope of inclusive innovation which requires further research, and includes questions such as: Can platforms foster inclusive innovation at a larger scale or are they intrinsically linked to a local context? How do platforms enable broader institutional change for scaling inclusive innovation? What is the cost-effectiveness of IPs vis-à-vis other approaches to inclusive innovation? Answering these questions is key to informing the development of inclusive innovation support policies.

\section{Acknowledgements}

The authors wish to thank the project teams from BAIF and CARE for sharing their experiences with us. We also wish to thank Alan Duncan (ILRI), Richard Heeks (University of Manchester), Suzan Cozzens (Georgia Institute of Technology), and two anonymous reviewers for their feedback on previous drafts. This article has been written in the context of the 'imGoats' project, financially supported by the European Commission through the International Fund for Agricultural Development (IFAD) [grant number C-ECG-45-ILRI].

\section{Note}

1. A value chain can be described as the set of actors and activities, and the relationships between them, to develop, produce, deliver, and maintain a product or service; a value chain approach intends to enhance value along the chain by linking supply and demand more effectively (World Bank 2007).

\section{References}

Amankwah, K., L. Klerkx, S. J. Oosting, O. Sakyi-Dawson, A. J. van der Zijp, and D. Millar. 2012. "Diagnosing Constraints to Market Participation of Small Ruminant Producers in Northern Ghana: An Innovation Systems Analysis." NJAS-Wageningen Journal of Life Sciences 60-63: 37-47. http://dx.doi.org/10.1016/j.njas.2012.06.002

Ayele, S., A. Duncan, A. Larbi, and T. T. Khanh. 2012. "Enhancing Innovation in Livestock Value Chains Through Networks: Lessons from Fodder Innovation Case Studies in Developing Countries." Science and Public Policy 39 (3): 333-346.

Boogaard, B. K., K. Swaans, S. C. J. Hendrickx, and M. Cosijn. 2013. "Reflection on Innovation Processes in a Smallholder Goat Development Project in Mozambique." In Innovation in Smallholder Farming in Africa: Recent Advances and Recommendations, edited by B. Triomphe, A. Waters-Bayer, L. Klerkx, M. Schut, B. Cullen, G. Kamau, and E. LeBorgne. Proceedings of the workshop on agricultural innovation systems in Africa (AISA), Nairobi, Kenya, May 29-31. pp. 67-71.

Cozzens, S., and J. Sutz. 2014. "Innovation in Informal Settings: Reflections and Proposals for a Research Agenda." Innovation and Development 4 (1): 5-31.

FARA (Forum for Agricultural Research in Africa). 2009. "Strategy and lessons sharing forum." Synthesis Report. Sub-Saharan Africa Challenge Program (SSA CP). www.fara-africa.org/media/uploads/library/ docs/ssacp/Strategy_meeting_final_report16_feb_2010.pdf

Foster, C., and R. Heeks. 2013a. "Conceptualising Inclusive Innovation: Modifying Systems of Innovation Frameworks to Understand Diffusion of New Technology to Low-Income Consumers." European Journal of Development Research 25 (3): 333-355. 
Foster, C., and R. Heeks. 2013b. "Analyzing Policy for Inclusive Innovation: The Mobile Sector and Baseof-the-pyramid Markets in Kenya." Innovation and Development 3 (1): 103-119.

Hounkonnou, D., D. Kossou, T. W. Kuyper, C. Leeuwis, E. S. Nederlof, N. Röling, O. Sakyi-Dawson, M. Traoré, and A. van Huis. 2012. "An Innovation Systems Approach to Institutional Change: Smallholder Development in West Africa." Agricultural Systems 108: 74-83. http://dx.doi.org/10.1016/j.agsy.2012. 01.007

Kilelu, C. W., L. Klerkx, and C. Leeuwis. 2013. "Unravelling the Role of Innovation Platforms in Supporting Co-evolution of Innovation: Contributions and Tensions in a Smallholder Dairy Development Programme." Agricultural Systems 118: 65-77. http://dx.doi.org/10.1016/j.agsy.2013.03.003

Klerkx, L., A. Hall, and C. Leeuwis. 2009. "Strengthening Agricultural Innovation Capacity: Are Innovation Brokers the Answer?" International Journal of Agricultural Resources, Governance and Ecology $8(5 / 6): 409-438$.

Klerkx, L., B. Mierlo, and C. Leeuwis. 2012. "Evolution of Systems Approaches to Agricultural Innovation: Concepts, Analysis and Interventions." In Farming Systems Research into the 21st Century: The New Dynamic, edited by I. Darnhofer, D. Gibbon, and B. Dedieu, 457-483. Dordrecht: Springer Netherlands.

Leeuwis, C., and A. van den Ban. 2004. Communication for Rural Innovation: Rethinking Agricultural Extension. Oxford: Blackwell Science.

Lundvall, B-Å. 2011. "Notes on Innovation Systems and Economic Development." Innovation and Development 1 (1): 25-38.

van Mierlo, B., M. Arkesteijn, and C. Leeuwis. 2010. "Enhancing the Reflexivity of System Innovation Projects with System Analyses." American Journal of Evaluation 31 (2): 143-161.

Nederlof, S., M. Wongtschowski, and F. van der Lee. eds. 2011. Putting Heads Together: Agricultural Innovation Platforms in Practice. Bulletin 396. Amsterdam: KIT publishers.

Ngwenya, H., and J. Hagmann. 2011. "Making Innovation Systems Work in Practice: Experiences in Integrating Innovation, Social Learning and Knowledge in Innovation Platforms." Knowledge Management for Development Journal 7 (1): 109-124.

Njuki, J., P., Pali, K. Nyikihadzoi, P. Olaride, and A. Adekunle. 2010. Monitoring and Evaluation Strategy for the Sub-Saharan Africa Challenge Program. Accra: FARA.

Pittaway, L., M. Robertson, K. Munir, D. Denyer, and A. Neely. 2004. "Networking and Innovation: A Systematic Review of the Evidence." International Journal of Management Reviews 5 (3-4): 137-168.

Röling, N. 1994. "Platforms for Decision Making About Ecosystems." In The Future of the Land: Mobilizing and Integrating Knowledge for Land Use Options, edited by L. O. Fresco, L. Stroosnijder, J. Bouma, and H. van Keulen, 385-393. Chichester: John Wiley and Sons.

van Rooyen, A., and S. Homann-Kee Tui. 2009. "Promoting Goat Market and Technology Development in Semiarid Zimbabwe for Food Security and Income Growth.” Tropical and Subtropical Agroecosystems 11 (1): $1-5$.

Swaans, K., J. E. W. Broerse, M. Salomon, M. Mudhara, M. Mweli, and J. F. G. Bunders. 2008. "The Farmer Life School: Experience from an Innovative Approach to HIV Education Among Farmers in South Africa." SAHARA J 5 (2): 52-64.

Szogs, A., A. Cummings, and C. Chaminade. 2011. "Building Systems of Innovation in Less Developed Countries: The Role of Intermediate Organizations Supporting Interactions in Tanzania and El Salvador." Innovation and Development 1 (2): 283-302.

Vorley, B., E. del Pozo-Vergnes, and A. Barnett. 2012. Small Producer Agency in the Globalised Market: Making Choices in a Changing World. London: IIED; The Hague: HIVOS.

Wennink, B., and W. Ochola. 2011. "Designing Innovation Platforms." In Putting Heads Together: Agricultural Innovation Platforms in Practice, edited by S. Nederlof, M. Wongtschowski, and F. van der Lee, 30-42. Bulletin 396. Amsterdam: KIT publishers.

World Bank. 2007. Enhancing Agricultural Innovation: How to Go beyond the Strengthening of Research Systems. Washington, DC: World Bank.

Yin, R. K. 2003. Case Study Research: Design and Methods. 3rd ed. Thousand Oaks, CA: Sage. 